\title{
Tension Perpendicular to Grain Strength of Wood, Laminated Veneer Lumber (LVL), and Cross-Banded LVL (LVL-C)
}

\author{
M. Ardalany
}

PhD candidate, Department of Civil and Natural Resources Engineering, University of Canterbury, Christchurch, New Zealand, Email: mar149@canterbury.ac.n

\section{B. Deam}

Senior Lecturer, Department of Civil and Natural Resources Engineering, University of Canterbury, Christchurch, New Zealand, Email: Bruce.deam@canterbury.ac.nz

\section{Fragiacomo}

Associate Professor, Department of Architecture, Design and Urban Planning, University of Sassari, Italy, Email: fragiacomo@uniss.it

\section{K.I. Crews}

Professor of Structural Engineering, Centre for Built Infrastructure Research, University of Technology, Sydney, Australia,Email: keith.crews@uts.edu.au

\begin{abstract}
Recent experimental tests carried out on structural timber members have highlighted the importance of tension perpendicular to grain strength, particularly in beams with holes and notches, in connection regions, in curved beams, and in post-tensioned timber frames. Innovative engineered wood products such as Cross Banded Laminated Veneer Lumber (LVL-C) have been introduced into the market specifically to improve the perpendicular to grain properties of normal Laminated Veneer Lumber (LVL).
\end{abstract}

This paper reports the results for a series of perpendicular to grain tension tests that were performed at the University of Canterbury using specimens of sawn timber Radiata Pine, LVL and LVL-C. The perpendicular to grain tension strengths of LVL were generally lower than those for sawn timber, but the LVL-C showed a significantly improved perpendicular to grain tensile strength. The paper also compares the experimental results with strengths predicted using both coupled elastic Finite Element Method (FEM) and Linear Elastic Fracture Mechanics (LEFM) models. These models were found to predict the average strength with reasonable accuracy.

KEYWORDS:Timber, Wood, LVL, LVL-C, perpendicular to grain, FEM, LEFM, strength.

\section{INTRODUCTION}

Wood as an orthotropic material has different material properties in different directions. The best material properties of wood are those stressing the material in the grain direction while the perpendicular properties are remarkable weaker. The low perpendicular to grain strength and stiffness of wood provides the potential for failure if not properly accounted for in design.

The low tensile strength of wood in perpendicular to grain direction may be reduced even further by introducing holes, notches and other stress concentrators, which cause a significant increase in tension stresses perpendicular to grain.

Many procedures in the design of wood members avoid high stresses in perpendicular to grain direction, however, sometimes it becomes inevitable. Two methods of mitigating this deficiency in wood products are reinforcing locally using screws and ro- tating some of the laminates so they are perpendicular to their original direction (e.g. like plywood).

Engineered wood products such as Laminated Veneer Lumber (LVL) and Cross Banded Laminated Veneer Lumber (LVL-C) have been introduced into market to improve consistency and other material properties of sawn timber. LVL is made of nominally $3 \mathrm{~mm}$ thick Radiata pine veneers that are glued and pressed together. The $3 \mathrm{~mm}$ veneer thickness was chosen to avoid crack propagation from one veneer to adjacent veneers(Dean et al. 1982). In LVL all of the veneers are aligned in one direction while in LVL-C a small portion of the longitudinal veneers are perpendicular to the others to improve the tension perpendicular to grain strength. The production is similar to plywood except normally only two of the laminates are rotated (the third laminate from each surface to maintain symmetry) to improve the perpendicular properties, without reducing the parallel to grain strength and stiffness too significantly. 


\section{EXPERIMENTS}

An experimental program was developed to provide a qualitative comparison of the perpendicular to grain strength of the Radiata pine used for construction in New Zealand. The experiments evaluated the approximate strength and its coefficient of variation (COV) for sawn timber, LVL and LVL-C. A total of 117 samples were tested. Important sample properties are summarized in Table 1 . The specimens were prepared according to ASTM D143-94 standard (ASTM D143-94 2000).

Table 1. Radiata pine specimens.

\begin{tabular}{cccccc}
\hline \multirow{2}{*}{$\begin{array}{c}\text { Material } \\
\text { Radiata }\end{array}$} & Number & $\begin{array}{c}\text { Thick- } \\
\text { ness }\end{array}$ & $\begin{array}{c}\text { Moisture } \\
\text { content }\end{array}$ & \multicolumn{2}{c}{ Number of veneers } \\
\cline { 5 - 6 } & & $(\mathrm{mm})$ & $(\%)$ & Perp* & Para** \\
\hline LVL & 57 & 50 & 9.3 & 0 & 16 \\
LVL-C & 30 & 35 & 11.7 & 2 & 8 \\
$\begin{array}{c}\text { Sawn } \\
\text { timber }\end{array}$ & 30 & 50 & 11.0 & - & - \\
\hline
\end{tabular}

* Perpendicular, ** Parallel

\subsection{Specimen preparation and testing}

The sawn timber was purchased from a local supplier with samples cut from randomly selected sticks. All of the LVL-C was cut from a single billet. A more extensive sampling strategy was employed for the LVL to provide better material statistics. Samples of LVL were selected from a single production run from one manufacturer and from different production runs from the other manufacturer.

The specimens were cut to size using an electric saw and drilled with a low speed drill to avoid forming additional cracks around the hole edges. The specimen shape and dimensions are shown in Figure 1. After cutting, the specimens were measured using a micrometer with accuracy of $0.01 \mathrm{~mm}$. The moisture content of specimens was measured by oven drying randomly selected specimens after they had been tested. The moisture content was measured in accordance with ASTM D4442-92 (ASTM D4442-92 2000).
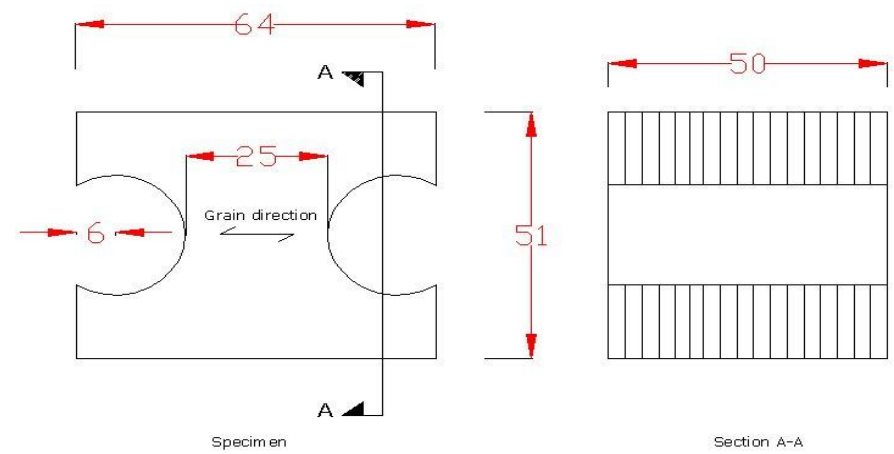

Figure 1. Geometry of specimens (dimensions in $\mathrm{mm}$ )
A universal testing machine was used for the testing. The specimens were inserted into steel jaws of the universal testing machine (see Figure 2), which were pulled apart at a rate of $2 \mathrm{~mm} / \mathrm{min}$. Universal joints were provided above and below the jaws, and load was measured using a $10 \mathrm{kN}$ load cell calibrated to class 1 of BS1610[4]. The force measurements were acquired at $10 \mathrm{~Hz}$ during the test.

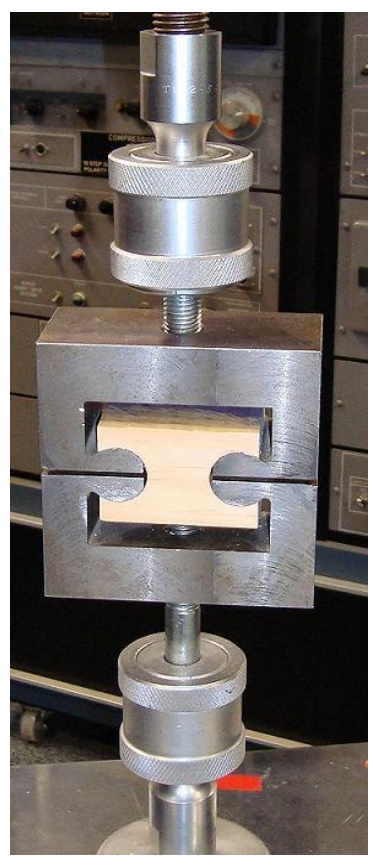

Figure 2. Set-up of experiments

\subsection{Experimental observations}

The crack surfaces within the sawn timber specimens mostly followed the growth rings, with occasional steps through the rings. The fracture surfaces were smooth in comparison to those for LVL where they were very jagged as the cracks propagated between laminates.

A range of fracture mechanisms were observed. The crack surface profiles are summarized in Figure 3. The sawn timber was vey brittle when it fractured whereas the LVL was less brittle.

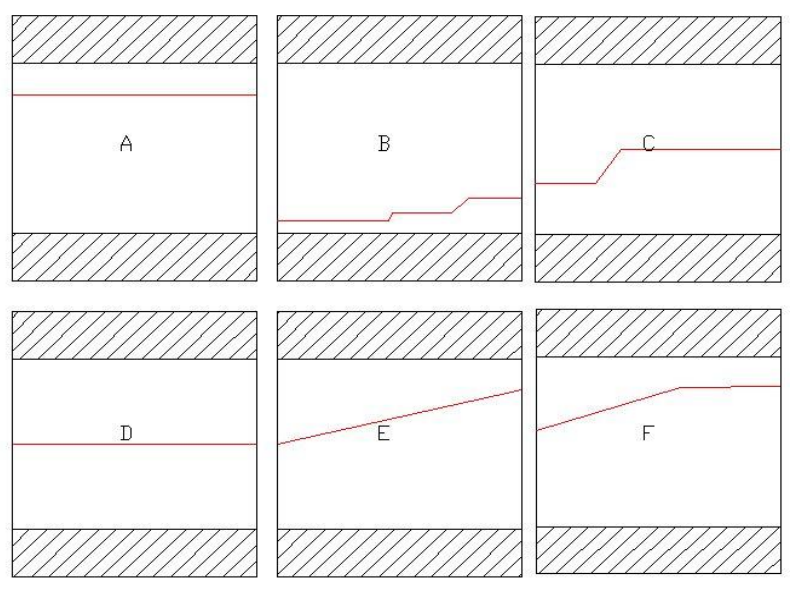

Figure 3. Crack surface profiles for sawn timber (section A-A of Figure 1) 

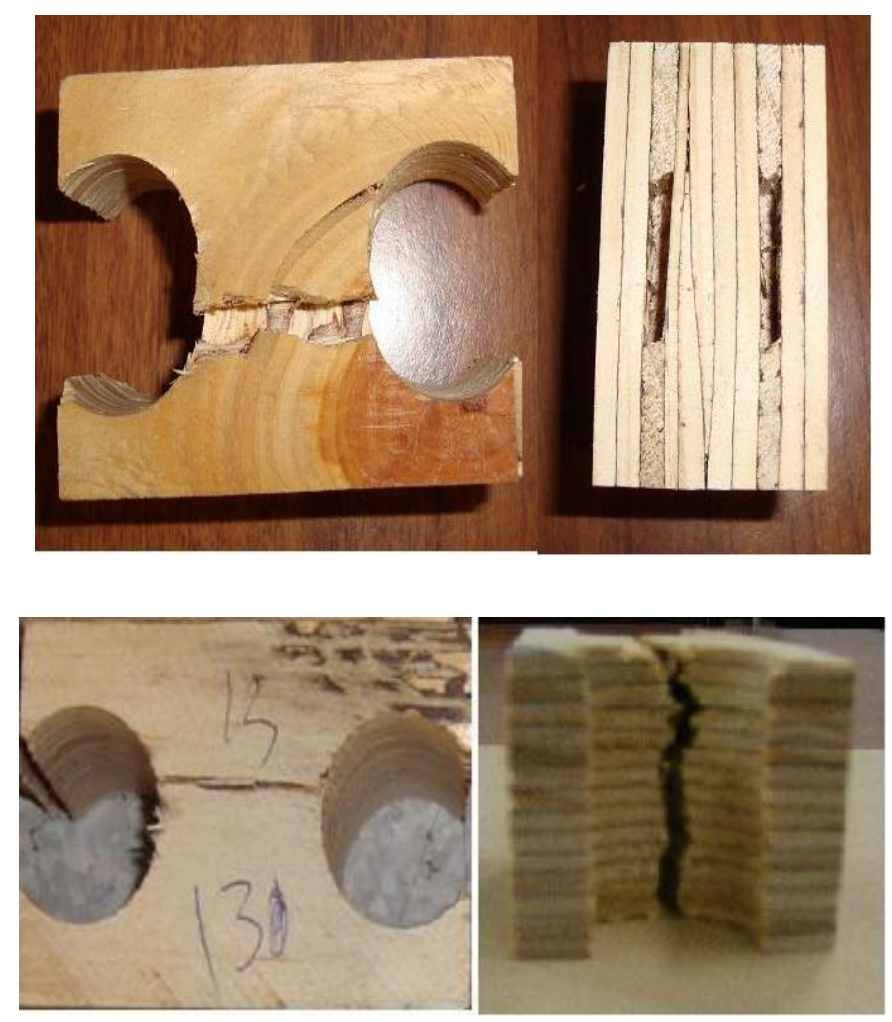

Figure 4. Glue shearing separation (up) and normal LVL fracture (Bottom)

Cracks developed in the middle of the LVL specimens and propagated in reasonably straight lines except some cases where the LVL crack approached a knot in one veneer. Knots and other defects appeared to slightly increase the tension perpendicular to grain strength.

The specimens of LVL tended to start crack initiation and propagation from one edge to other edge.

The crack surfaces within LVL-C were relatively similar to those in LVL except the veneers loaded parallel to grain either fractured (3 specimens) or remained intact but separated from their adjacent laminates (X specimens) as shown in Figure 4, with as many specimens shearing along the glue line as along the grain).

There were no fractures of the type shown in Figure 5 and reported by Hummer et al. (Hummer et al. 2006), where the top right portion of the specimen broke off due to a form of flexural cracking. This could be due to the higher shear and tensile strengths Table 2. Calculated tensile strength of the material

\begin{tabular}{cccccc}
\hline Specimen & Selecting process & $\begin{array}{c}\text { Average ten- } \\
\text { sile strength } \\
(\mathrm{MPa})\end{array}$ & $\begin{array}{c}\text { Minimum ten- } \\
\text { sile strength } \\
(\mathrm{MPa})\end{array}$ & $\begin{array}{c}\text { Coefficient of } \\
\text { variation } \\
(\%)\end{array}$ & $\begin{array}{c}5^{\text {th }} \text { percentile of } \\
\text { the values } \\
(\mathrm{MPa})\end{array}$ \\
\hline LVL & Random & 2.021 & 1.152 & 18 & 1.434 \\
$\begin{array}{c}\text { LVL-C } \\
\text { Sawn }\end{array}$ & Cut from 1 billet & 7.540 & 5.827 & 10 & 6.495 \\
timber & Random & 3.887 & 2.662 & 23 & 3.018 \\
\hline
\end{tabular}

\section{PREDICTING TENSILE FAILURE LOAD}

The Finite Element Method (FEM), Linear Elastic Fracture Mechanics (LEFM), and the initial crack of the New Zealand pine used to manufacture the LVL.

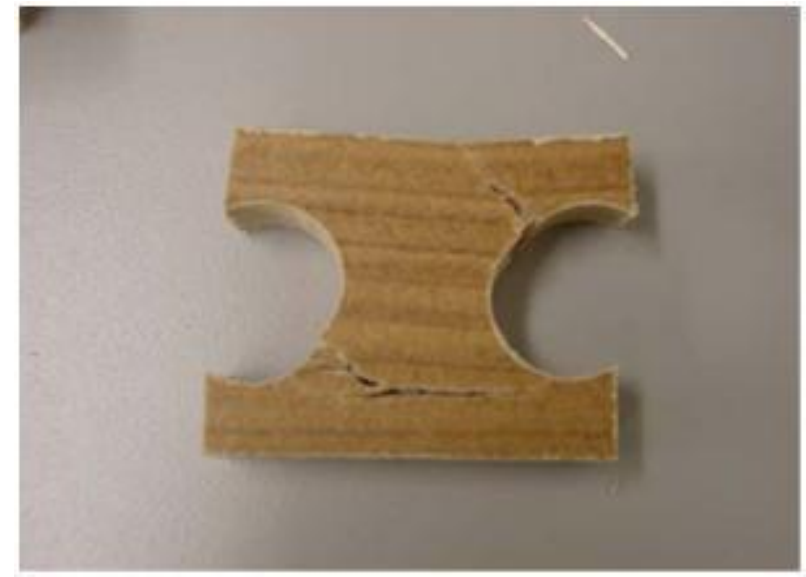

Figure 5 Failure of specimens in upper right part (Hummer et al. 2006)

\subsection{Tensile strengths}

The calculation of the tension strength of the material was performed by dividing the load by the measured surface area of the fracture before testing. Table 2 summarizes the results of the strength calculations for three sets of experiments. The results of the experiments show higher strength values for sawn timber in comparison to LVL. This could be due to either twisting of the fibers in the sawn timber or micro-cracking of the LVL veneers during the production process. This is in good match with the (Hummer et al. 2006).

Table 2 also shows that like all other material strength properties, the COV of LVL is lower than it is for the original material. However, it is not as significantly lower as the typical modulus of elasticity and modulus of rupture for LVL.

A comparison between LVL and Glulam, which has strength about 3MPa (Gustafsson 1993), shows better properties for Glulam but when LVL-C is used the situation changes markedly due to the rotated veneers, with the strength of the material increasing about 2.5 times than Glulam. This will make LVL-C a very good option for the cases where there are hole and notches in the member. method were all used to predict the tension perpendicular to grain strength of LVL specimens.

The procedure for modeling and predicting the failure load is summarized as: 
1. Finite element modeling of the specimens using shell elements to estimate the most likely location of crack initiation and propagation.

2. Cracks were introduced into model using 'seam' elements; where the seam is a crack that opens when loaded.

3. The length of the crack was calculated using the initial crack method (Gustafsson 1993)

4. The crack tip was modeled using special elements (Ardalany et al. 2010)

5. The stress intensity factors were calculated using ABAQUS software (Habbitt et al. 2007)

6. The failure load was calculated using Wu's mixed mode fracture criterion $(\mathrm{Wu} 1967 ; \mathrm{Wu}$ 1968).

The LVL specimens in the ABAQUS software package were modeled using $50 \mathrm{~mm}$ thick planner shell elements. LVL was assumed to be elastic orthotropic with material properties given in Table 3 (Ardalany et al. 2010).

Table 3: Material properties of LVL

\begin{tabular}{cccc}
\hline $\mathrm{E}_{\mathrm{x}}(\mathrm{MPa})$ & $E_{y}(\mathrm{MPa})$ & $G_{x y}(\mathrm{MPa})$ & $\vartheta_{\mathrm{xy}}$ \\
\hline 12000 & 600 & 1000 & 0.3 \\
\hline
\end{tabular}

$\mathrm{E}_{\mathrm{x}}$ and $E_{y}$ are the elastic moduli parallel and perpendicular to grain, respectively, $G_{x y}$ is the shear strength, and $\vartheta_{x y}$ signifies the Poisson's ratio.

The element mesh was created with emphasis on minimizing both the mesh distortion and transition. Quad elements (S8R) were used for the meshing. The resulting mesh and the principal stress contours are displayed in Figure 6. The $1 \mathrm{kN}$ uniformly distributed load was applied over the middle upper curved edges of the model and lower curved edges were also used for the supports.

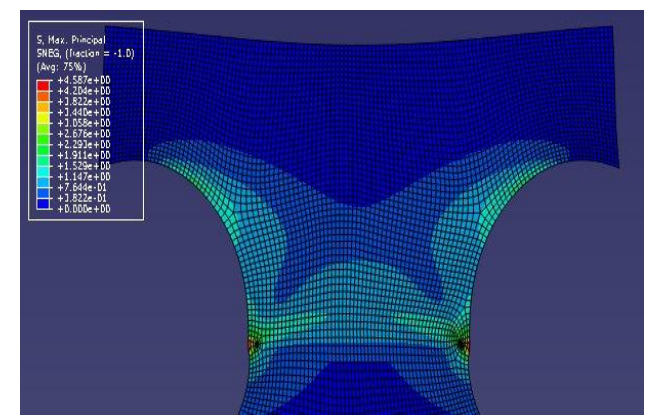

Figure 6. Maximum Principal stresses (deformed shape)

As expected, Figure 6 shows the greatest stress intensities at the specimen centerline. However, there are also significant stresses closer to the jaw contact positions which accounts for secondary fracture illustrated in Figure 6.
For step 2, modeling the fracture, seam elements were introduced into the high stressed area to model the crack opening as the seam elements are separated. Very fine meshing was used at the crack tip. The tip itself was modeled with a ring of triangular elements type S8R5, which are 8node doubly curved thin shells with reduced integration, and five degrees of freedom per node. The rest of the model was meshed with the S8R 8 -node doubly curved thick shells, also with reduced integration. The option to minimize mesh transition was selected to avoid extra mesh deformation.

In order to improve accuracy of the calculations, the middle node closest to the crack tip was moved to the half length to create singularity of $1 / \sqrt{r}$ (Ardalany et al. 2010), where $\sqrt{r}$ is the distance from crack tip (see Figure 7).

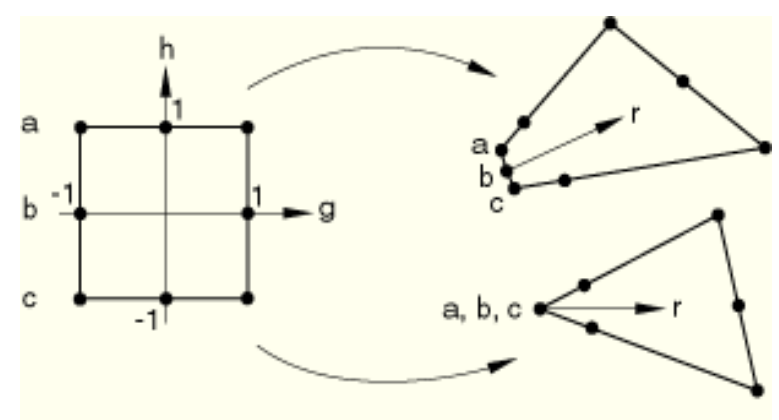

isoparametric space

Figure 7:Meshing for modeling of singularity (Habbitt et al. 2007)

The elastic model was then analyzed and the stress intensity factors in mode I and II calculated.

The crack length was calculated using the initial crack approach. In this method, a crack with finite length is introduced into the model. The length is calculated using the formulas recommended by Gustafsson (Gustafsson 1993).

$$
\begin{gathered}
2 x_{0}=\frac{2}{\pi} \frac{E_{I} G_{I c}}{f_{t}^{2}} \frac{E_{x}}{E_{y}}\left(\frac{G_{I I c}}{G_{I c}}\right)^{2} \frac{1}{4 k^{4}}\left\{\sqrt{1+4 k^{2} \sqrt{\frac{E_{y}}{E_{x}}} \frac{G_{I c}}{G_{I I c}}}\right. \\
-1\}^{2}\left\{1+\frac{k^{2}}{\left(\frac{f_{v}}{f_{t}}\right)^{2}}\right\} \\
\frac{1}{E_{I}}=\frac{1}{E_{x}} \sqrt{\frac{E_{x}}{2 E_{y}} \sqrt{\sqrt{\frac{E_{x}}{E_{y}}}+\frac{E_{x}}{2 G_{x y}}-\vartheta_{y x} \frac{E_{x}}{E_{y}}}} \\
\frac{1}{E_{I I}}=\frac{1}{E_{x}} \sqrt{\frac{1}{2} \sqrt{\frac{E_{x}}{E_{y}}+\frac{E_{x}}{2 G_{x y}}-\vartheta_{y x} \frac{E_{x}}{E_{y}}}}
\end{gathered}
$$


In this formulation, $\mathrm{x}_{0}$ is the crack length which is twice the crack length obtained using the mean stress criterion method, $x_{0}$ is the shear strength of the material in the crack plane, $f_{t}$ is the tensile strength of the LVL experimentally obtained, $\mathrm{G}_{\text {Ic }}$ and $\mathrm{G}_{\text {IIc }}$ are the critical energy release rate values in mode I and II respectively, $k$ is the mixed mode ratio defined as $\mathrm{K}_{\mathrm{II}} / \mathrm{K}_{\mathrm{I}}$ and finally $\mathrm{E}_{\mathrm{I}}$ and $\mathrm{E}_{\mathrm{II}}$ are the equivalent modulus of elasticity for orthotropic materials calculated from above formulas. The stress intensity factors can be obtained from the energy release rate values using the following equations:

$$
\begin{gathered}
K_{I}=\sqrt{E_{I} G_{I}} \\
K_{I I}=\sqrt{E_{I I} G_{I I}}
\end{gathered}
$$

For pure mode $\mathrm{I}(\mathrm{k} \rightarrow 0)$ the crack length formulation can be simplified as follows:

$$
2 x_{0}=\frac{2}{\pi} \frac{E_{I} G_{I C}}{f_{t}^{2}}
$$

Similarly, for pure mode II $(\mathrm{k} \rightarrow \infty)$ can be simplifies to:

$$
2 x_{0}=\frac{2}{\pi} \frac{E_{I I} G_{I I C}}{f_{v}^{2}}
$$

For the experimentally measured mode I of fracture $K_{I c}=0.354 \mathrm{MPa} \sqrt{\mathrm{m}}$ (Ardalany et al. 2010; Ardalany et al. 2010) and the tensile strength calculated from current experiments, the crack length was estimated to be $9.4 \mathrm{~mm}$.

By introducing the crack length in the model and obtaining the stress intensities at the crack tip, the failure load can be calculated using the Wu's mixed mode fracture criterion (Ballerini \& Rezzi 2001; Ballerini \& Rizzi 2007).

$$
\frac{K_{I}}{K_{I C}}+\left(\frac{K_{I I}}{K_{I C}}\right)^{2}=1
$$

In the above formulation $\mathrm{K}_{\mathrm{IC}}$ and $\mathrm{K}_{I I C}$ are the fracture toughness of LVL in mode I and II, respectively. For pure mode I and mode II the equation (8) becomes:

$$
\begin{gathered}
K_{I}=K_{I c} \\
K_{I I}=K_{I I c}
\end{gathered}
$$

Figure 8 shows the deformed model with the cracks. Around the crack, a half circle partition was considered to avoid using of very fine elements for other parts of the specimen and speeding up the analysis.

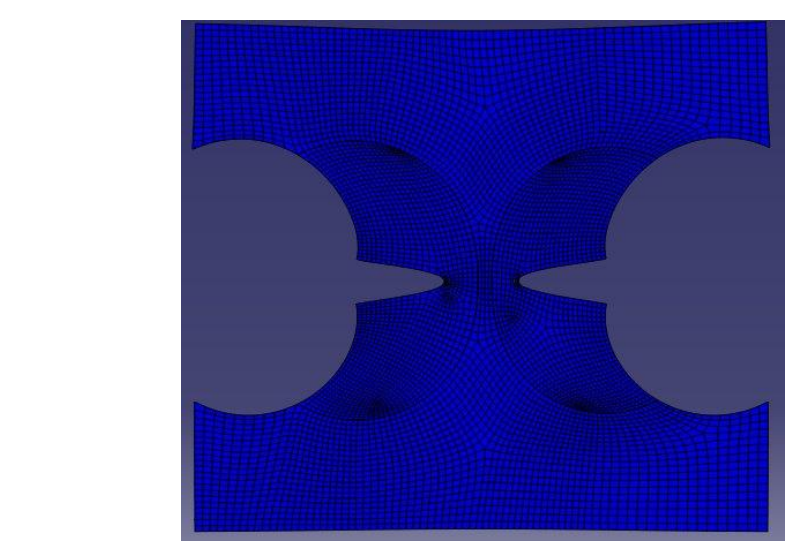

Figure 8: Specimen with cracks after deformation

ABAQUS calculations of stress intensity factors make use of the contour integrals. The software automatically detects the mesh around the crack tip and calculates the stress intensities from the deformations with the adjoining elements using the displacement extrapolation method(Ballerini \& Rezzi 2001). However, additionally layers of elements are used to calculate the stress intensity factors.

ABAQUS calculates the stress intensities factors from the deformations of rings of elements using an appropriate formulation, based on displacements, the so-called displacement extrapolation technique(Chen \& Kuang 1992; Guinea et al. 2000). However, other energy based methods can be used to calculate the energy required to close the crack.

The calculated stress intensity factors using the first five contour integrals are presented in Table 4. As expected, mode II had little influence on the results because opening is the dominating mode of deformation.

Table 4. Calculated stress intensity factor $\times\left(10^{-3}\right)$

$\begin{array}{cccccc}\text { Contour } & 1 & 2 & 3 & 4 & 5 \\ \text { Mode I } & 5.630 & 5.696 & 5.605 & 5.572 & 5.614 \\ \text { Mode II } & 0.4590 & 0.3597 & 0.3645 & 0.4622 & 0.4739\end{array}$

The calculated failure loads using different contour integrals are shown in Table 5.

Table 5. Predicted failure load for LVL using different contours

\begin{tabular}{cccccc}
\hline Contours & 1 & 2 & 3 & 4 & 5 \\
\hline $\begin{array}{c}\text { Load } \\
(\mathrm{kN})\end{array}$ & 2.66 & 2.63 & 2.68 & 2.69 & 2.67 \\
\hline
\end{tabular}

The first few contour integrals are usually ignored because they are very close to the crack tip and may give quite unrealistic values (Habbitt et al. 2007). The third contours predicted load is $2.68 \mathrm{kN}$ which was quite close to the average experimental load for the LVL which was $2.53 \mathrm{kN}$.

\section{DISCUSSION}

The tension perpendicular to grain strength of LVL, LVL-C and Sawn timber radiata pine was measured 
experimentally and predicted using coupled numerical analysis.

Experiments showed better tension perpendicular to grain strength for sawn timber than LVL, however LVL-C exhibited significantly higher tensile strength perpendicular to grain.

The low tension perpendicular to grain makes LVL susceptible to crack initiation and propagation around holes, notches, splits and joints. Special care should therefore be given to the design of these members. A good solution could be to use LVL-C when there are notches and other stress concentrators. The rotated grain of the LVL-C, in fact, significantly increases the strength of the material in the perpendicular to the grain direction.

Numerical analyses were found to be in good agreement with the experiments. The initial crack method appears to provide the best approach for estimating the crack length for calculation of stress intensities used in fracture mechanics to predict the failure load.

\section{ACKNOWLEDGMENTS}

The Authors would like to extend their gratitude to the Department of Civil and Natural Resources Engineering of University of Canterbury, New Zealand, for providing the $\mathrm{PhD}$ scholarship to support the first author; Warwick Banks and Andrew Vanhoutte for providing material; Dr. David Carradine for the useful comments; and the technical support of laboratory technicians from the University of Canterbury, especially Alan Poynter.

\section{REFERENCES}

Ardalany, M., Deam, B. \& Fragiacomo, M. (2010). Numerical investigation of the load carrying capacity of laminated veneer lumber joists with holes. World Conference WCTE2010. Trentino, Italy

Ardalany, M., Deam, B., Fragiacomo, M. \& Crews, K. (2010). "Experimental results of fracture toughness evaluation of radiata pine laminated veneer lumber (LVL) in mode II (shearing)." Journal of Structural Engineering (unpubl.).

Ardalany, M., Deam, B., Fragiacomo, M. \& Crews, K. (2010). "Experimental results of fracture energy and fracture toughness evaluation of radiata pine laminated veneer lumber (LVL) in mode I (opening)." Journal of materials and structures RILEM (TO BE PUBLISHED).

ASTM D143-94 (2000). Standard test method for small clear specimens of timber West Conshohocken, ASTM International.

ASTM D4442-92 (2000). Standard test methods for direct moisture content measurement of wood and wood-based materials. West Conshohocken, ASTM International.

Ballerini, M. \& Rezzi, R. (2001). Numerical LEFM analyses for the evaluation of failure loads of beams loaded perpendicular to grain by single dowel connections. CIB-W18 conference. Venice, Italy: Paper 34-7-2.

Ballerini, M. \& Rizzi, M. (2007). "Numerical LEFM analyses for the prediction of the splitting strength of beams loaded perpendicular-to-grain by dowel-type connections." Journal of Materials and Structures 40(1): 139-149.

Chen, L. S. \& Kuang, J. H. (1992). "A displacement extrapolation method for determining the stress intensity factors along flaw border." International Journal of Fracture 57(4): R51-R58.

Dean, J., Gibson, J. A. \& Moss, P. J. (1982). The fracture properties of timber. Timber Engineering. University of Canterbury, Christchurch, New Zealand: 97-115.

Guinea, G. V., Planas, J. \& Elices, M. (2000). "KI evaluation by the displacement extrapolation technique." Journal of Engineering fracture mechanics 66(3): 243-255.

Gustafsson, P. (1993). Fracture Mechanics Models for Strength Analysis of Timber Beams with a Hole or a Notch - A Report of RILEM TC-133 : Mean stress approach and initial crack approach (paper in report). Sweden, Lund University. Report TVSM-7134 1-15.

Habbitt, Karlsson \& Sorensen (2007). ABAQUS, Theory Manual, Version 6.7-1, ABAQUS Inc.

Habbitt, Karlsson \& Sorensen (2007). ABAQUS, User Manual, Version 6.7, ABAQUS Inc.

Hummer, T., Dolan, D. \& Wolcott, M. (2006). Tension perpendicular to grain of wood, Lamianted Veneer Lumber, and a Wood Plastic Composite. 9th world conference on timber engineering (WCTE2006). Portland.

Wu, E. M. (1967). "Application of fracture mechanics to anisotropic plates." Journal of Applied Mechanics 34(4): 967-\&.

Wu, E. M. (1968). "Application of fracture mechanics to anisotropic plates." Journal of Mechanical Engineering 90(4): 134-\&. 